\title{
Oxidative Damage in the Aging Heart: an Experimental Rat Model
}

\author{
Gustavo Lenci Marques ${ }^{1, *}$, Francisco Filipak Neto ${ }^{2}$, Ciro Alberto de Oliveira Ribeiro ${ }^{2}$, Samuel \\ Liebel $^{2}$, Rogério de Fraga ${ }^{3}$ and Ronaldo da Rocha Loures Bueno ${ }^{1}$ \\ ${ }^{1}$ Internal Medicine Department - Universidade Federal do Paraná, Brazil \\ ${ }^{2}$ Cell Biology Department - Universidade Federal do Paraná, Brazil \\ ${ }^{3}$ Surgery Department - Universidade Federal do Paraná, Brazil
}

\begin{abstract}
Introduction: Several theories have been proposed to explain the cause of 'aging'; however, the factors that affect this complex process are still poorly understood. Of these theories, the accumulation of oxidative damage over time is among the most accepted. Particularly, the heart is one of the most affected organs by oxidative stress. The current study, therefore, aimed to investigate oxidative stress markers in myocardial tissue of rats at different ages. Methods: Seventy-two rats were distributed into 6 groups of 12 animals each and maintained for 3, 6, 9, 12, 18 and 24 months. After euthanasia, the heart was removed and the levels of non-protein thiols, lipid peroxidation, and protein carbonylation, as well as superoxide dismutase and catalase activities were determined. Results: Superoxide dismutase, catalase activity and lipid peroxidation were reduced in the older groups of animals, when compared with the younger group. However, protein carbonylation showed an increase in the 12-month group followed by a decrease in the older groups. In addition, the levels of non-protein thiols were increased in the 12-month group and not detected in the older groups. Conclusion: Our data showed that oxidative stress is not associated with aging in the heart. However, an increase in non-protein thiols may be an important factor that compensates for the decrease of superoxide dismutase and catalase activity in the oldest rats, to maintain appropriate antioxidant defenses against oxidative insults.
\end{abstract}

Keywords: Aging, Catalase, Glutathione, Lipid Peroxidation, Protein Carbonylation, Rat, ROS, Superoxide Dismutase.

\section{INTRODUCTION}

Aging is inevitable and occurs across all kingdoms, culminating in functional deterioration of multiple systems, leading to increased morbidity and mortality [1]. In the last century, with the improvements in public health and the increase of life expectancy, knowledge about the processes involved in physiological aging became essential. Therefore, numerous researchers have proposed theories of the mechanisms related with the aging process [2]. Oxidative Damage Theory is one such theory, which has been discussed and investigated since the 1950s [3], where the accumulation of oxidative damage due to cellular metabolism is proposed. Additionally, the imbalance of antioxidant defenses may be the cause of damaged cellular macromolecules such as DNA, proteins and lipids, leading to functional failure and cell death [3-5].

The heart is an organ with high oxygen consumption, high cellular longevity, and low turnover of antioxidant molecules. Therefore, it is known to produce high levels of free radicals and accumulate oxidative damage over time, which makes it particularly sensitive to oxidative stress [68].

*Address correspondence to this author at the 181 General Carneiro St., Alto da Gloria, Curitiba, PR, Brazil, Zip Code: 80.060-900;

Tel: +55 41 9149-1428; Fax: +55 41 33607832;

E-mail: gustavolencimarques@gmail.com
Previous studies have found heart disease, such as coronary disease and heart failure, to be correlated with increased oxidative damage to myocardial cells [9-12]. Data from the Centers for Diseases Control and Prevention (CDC) support this notion, revealing that cardiovascular systemrelated diseases were the leading cause of death among the elderly, in 2013 [13]. Therefore, several studies have tried to correlate oxidative damage with the physiological aging [14, $15]$.

The current study aims to investigate the role of oxidative stress in physiological aging of the heart using rats of different ages as a model and quantify the main biomarkers of oxidative damage (lipid peroxidation and protein carbonylation) as well as the antioxidant defense system (non-protein thiols, catalase, and superoxide dismutase) in myocardial tissue.

\section{METHODS}

After the approval by Ethics Animal Experiment Committee of Federal University of Paraná (protocol number 23075.031142/2013-73), 72 male Wistar rats were housed in $60 \times 50 \times 22 \mathrm{~cm}$ cages (three rats per cage) and maintained at controlled temperature $\left(22^{\circ} \mathrm{C}\right)$, light cycle $(12 \mathrm{~h}$ light $/ 12 \mathrm{~h}$ dark) and food supply (standard pellet diet; NuvilabNuvital $^{\mathbb{Q}}$, Curitiba, Brazil) throughout the experimental period. 
A total of 6 groups were established, with 12 animals each, and the rats within these groups were euthanized after completing the following ages: 90 days (group 1), 180 days (group 2), 270 days (group 3), 360 days (group 4), 540 days (group 5) and 720 days (group 6). Before dissection of the heart, the rats were weighed, their heights measured, and anesthetized with intraperitoneal injection $\left(1 \mathrm{ml} \cdot \mathrm{kg}^{-1}\right)$ of ketamine hydrochloride solution $\left(57.67 \mathrm{mg} \cdot \mathrm{ml}^{-1}\right)$ associated with $2 \%$ xylazine hydrochloride. After anesthesia, thoracotomy was performed and the rats were euthanized by perfusion with $0.9 \% \mathrm{NaCl}$ solution at $0{ }^{\circ} \mathrm{C}$. The heart was removed immediately after this procedure.

Myocardial tissue was homogenized in ice-cold phosphate buffer saline (PBS), $\mathrm{pH} 7.4$ and centrifuged at $12000 \times \mathrm{g}$ for $20 \mathrm{~min}$ at $4{ }^{\circ} \mathrm{C}$. The supernatant was stored at $76^{\circ} \mathrm{C}$ for further analyses.

Biochemical procedures: protein content [16], nonprotein thiols concentration, NPT [17], lipid peroxidation, LPO $[18,19]$, superoxide dismutase, SOD [20] and catalase, CAT [21] were measured according to previously published protocols [22], with minor modifications. For protein content, NPT, LPO, and SOD, volumes were adjusted for reading the microplates, whereas hydrogen peroxide were adjusted to $30 \mathrm{mM}$ for the CAT assay. PCO was determined based on methods described by Levine et al. [23]. Protein concentration of the samples was adjusted to $2.0 \mathrm{mg} \cdot \mathrm{ml}^{-1}$ for determination of SOD, CAT, and PCO levels.

Statistical analysis: Data were initially tested for normality through the Shapiro-Wilk normality test. Next, data were $\log$-transformed and those biomarkers that had normal distribution (SOD, CAT, LPO, and non-protein thiols) were compared through one-way analysis of variance (ANOVA) followed by Tukey's post-hoc test. For protein carbonylation, groups were compared through nonparametric Wilcoxon method. Multivariate correlations were determined among all biomarkers. A value of $p<0.05$ was considered to statistically significant.

\section{RESULTS}

Lipid peroxidation levels did not vary with age, except for a few isolated comparisons among the groups. An example is the comparison between the youngest and the oldest groups, which revealed a statistically significant reduction in LPO in the oldest group (Fig. 1A).

Protein carbonylation increased progressively in rats up to the $12^{\text {th }}$ month and decreased significantly in the 18 - and 24-month groups (Fig. 1B).

CAT and SOD activities showed a trend of stable values during most of the animal's life, followed by a very sharp drop in the oldest group (Fig. 1C-D).

Non-protein thiols showed a $21 \%$ increase in the 12 month group followed by stable levels in the older rats (Fig. 1E).

It should be noted that all animals were alive throughout the periods established for the groups 1 to 6 . Furthermore, their weight increased until they reached the $12^{\text {th }}$ month of age, and then remained stable (Fig. 2).

\section{DISCUSSION}

The rats in the last group were 720 days old at the end of the study and might be considered old [24]. The gain of weight during the experiment was considered adequate in relation to the age standard curves [25].

The myocardial tissue of rats, lipid peroxidation and protein carbonylation levels did not have clear age-related patterns. Previous studies have demonstrated a downward trend of LPO, without statistical significance [14, 15]. However, compared to the current study, these studies used fewer rats distributed in fewer groups. Davydov and Shvets [26] studied the effects of immobilization stress in heart LPO of young and aged rats. When only the control group (not subjected to stress) was analyzed, there was no significant difference the levels of LPO markers in young and aged animals. Likewise, Farooqui et al. [27] performed a similar study using Sprague-Dawley rats and found an upward trend of LPO.

In our study, in a simple analysis and comparison between the youngest and oldest groups, a significant reduction of LPO is clearly observed in the latter group. A possible explanation for this finding is that myocardial oxygen consumption is significantly reduced at advanced ages, leading to a decreased production of Reactive Oxygen Species (ROS) and, consequently, less oxidative damage [28]. Protein carbonylation showed only a trend of progressive increase up to 12 months and a significant decrease in the 18- and 24-month groups. There are reports in the literatures that the heart suffers from cell death and replacement of cardiomyocytes (high in proteins) by fibrous tissue in the aged myocardial tissue [29], which could explain the PCO findings.

To maintain the intracellular redox milieu, SOD-CAT and/or non-protein thiols (mainly represented by glutathione, GSH) systems must operate in the cells. In our study, these systems were not altered during the rats' life, except for the oldest animals, i.e., 24-month group. SOD-CAT activities decreased whereas non-protein thiols levels increased, probably as a compensatory mechanism that was efficient enough to prevent increases of LPO and PCO.

Previous studies differences in this system during aging. Farooqui et al [27]. found a downward trend in GSH and Cand and Verdetti [15] did not find any difference for SOD, CAT, and GSH activity during aging. Likewise, Reiss and Gershon [30] reported a small downward trend in SOD activity of rats and mice in aging, but the authors did not test other antioxidant systems.

Based on the observation that the rats have reduced activities of SOD-CAT system, some inferences can be performed to understand why some heart diseases associated with oxidative damaged are more prevalent in aged people. Both coronary disease and heart failure have risk factors in common, such smoking and diabetes. Sekhar et al. [31] demonstrated that diabetic individuals have a deficiency in glutathione synthesis. Smoking has also been associated with reduction of glutathione levels in serum, and increases in oxidative damage markers [32]. Thus, these risk factors affect the major non-enzymatic antioxidant defense system, 

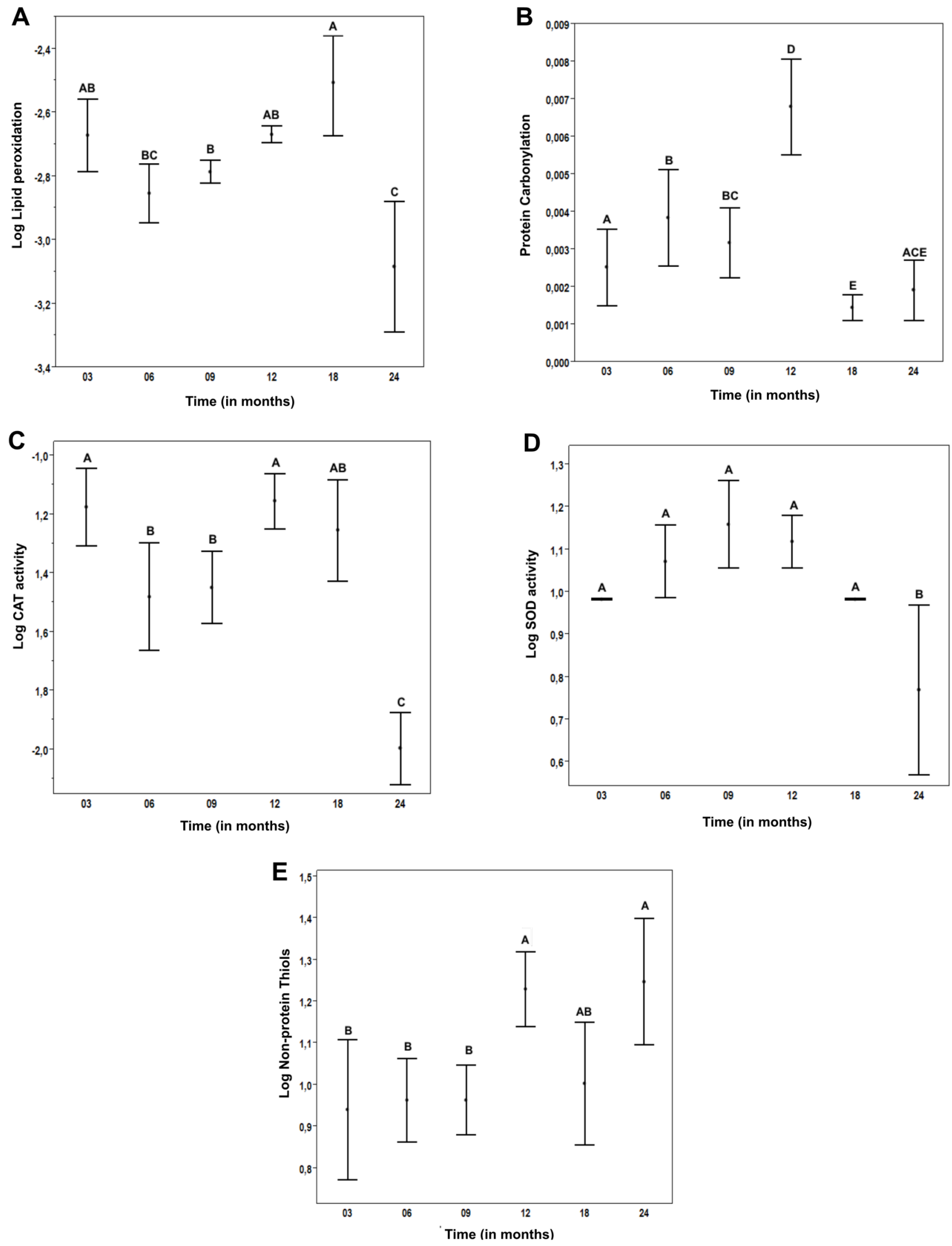

Fig. (1). A) $\log$ LPO results $\times$ Time. B) PCO results $\times$ Time. C) Log catalase activity $\times$ Time. D) Log SOD activity $\times$ Time. E) Log Nonprotein thiols $\times$ time. $*$ Values not connected by the same letters are statistically different. 


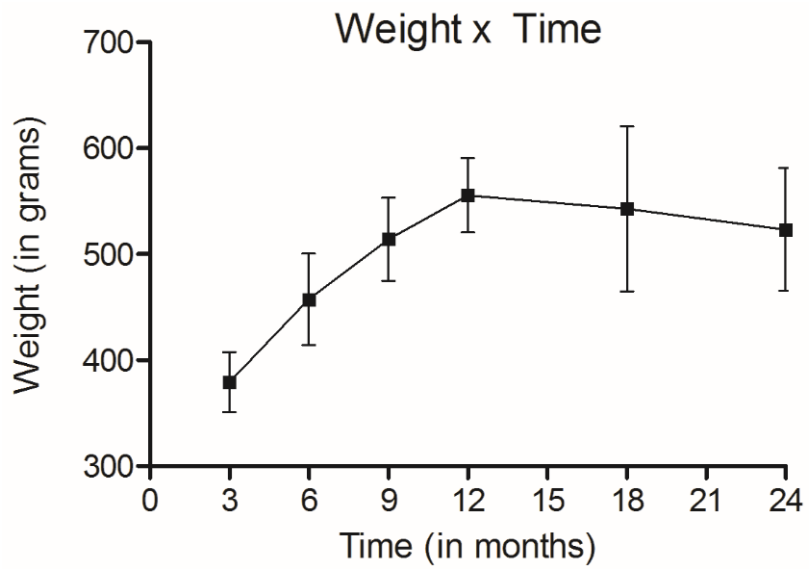

Fig. (2). Weight of rats during the experiment.

which has had a compensatory function for the SOD-CAT system in the current study, making the elderly particularly susceptible to these diseases.

Despite the understanding that good health and the onset of disease in the elderly is complex and multifactorial, these findings therefore help to understand how oxidative damage acts during aging.

However, based on the results of the current study, it is not possible to conclude that oxidative damage is the cause of aging in the heart. This is because the study is essentially descriptive and did not assess the cardiac structural aspect of animals with different levels of oxidative damage in aging markers. Another limitation arises from not having examined oxidative stress in other cellular structures such as mitochondria and DNA.

\section{CONCLUSION}

Myocardium aging does not seem to be caused by oxidative damage to cell lipids and proteins. However, increase of non-protein thiol levels may be an important factor that compensates for the decreases of SOD and CAT activities in the oldest group of rats, to maintain appropriate antioxidant defenses against oxidative insults.

\section{CONFLICT OF INTEREST}

The authors confirm that this article content has no conflict of interest.

\section{ACKNOWLEDGEMENTS}

I would like to acknowledge Angelina Caron Hospital for the Animal Facility Services.

\section{REFERENCES}

[1] Hayflick L. How and why we age. Exp Gerontol 1998; 33(7-8): 639-53.

[2] Jin K. Modern biological theories of aging. Aging Dis 2010; 1(2): $72-4$.

[3] Harman D. Aging: a theory based on free radical and radiation chemistry. J Gerontol 1956; 11(3): 298-300.
[4] Rikans LE, Hornbrook KR. Lipid peroxidation, antioxidant protection and aging. Biochim Biophys Acta 1997; 1362(2-3): 11627.

[5] Cui H, Kong Y, Zhang H. Oxidative stress, mitochondrial dysfunction, and aging. J Signal Transduct 2012; 2012: 646354.

[6] Molina H, García M. Enzymatic defenses of the rat heart against lipid peroxidation. Mech Ageing Dev 1997; 97(1): 1-7.

[7] Lakatta EG, Sollott SJ. Perspectives on mammalian cardiovascular aging: humans to molecules. Comp Biochem Physiol A Mol Integr Physiol 2002; 132(4): 699-721.

[8] Babusikova E, Jesenak M, Racay P, et al. Oxidative alternations in rat heart homogenate and mitochondria during ageing. Gen Physiol Biophys 2008; 27(2): 115-20.

[9] Dhalla NS, Temsah RM, Netticadan T. Role of oxidative stress in cardiovascular diseases. J Hypertens 2000; 18(6): 655-73.

[10] Grieve DJ, Shah AM. Oxidative stress in heart failure. More than just damage. Eur Heart J 2003; 24(24): 2161-3.

[11] Vichova T, Motovska Z. Oxidative stress: Predictive marker for coronary artery disease. Exp Clin Cardiol 2013; 18(2): e88-91.

[12] Vassalle C, Petrozzi L, Botto N, et al. Oxidative stress and its association with coronary artery disease and different atherogenic risk factors. J Intern Med 2004; 256(4): 308-15.

[13] Murphy SL, Xu J, Kochanek KD. Deaths: Final data for 2010. In: Statistics. National Vital Statistics Reports: National Center for Health Statistics 2013.

[14] Sawada M, Carlson JC. Changes in superoxide radical and lipid peroxide formation in the brain, heart and liver during the lifetime of the rat. Mech Ageing Dev 1987; 41(1-2): 125-37.

[15] Cand F, Verdetti J. Superoxide dismutase, glutathione peroxidase, catalase, and lipid peroxidation in the major organs of the aging rats. Free Radic Biol Med 1989; 7(1): 59-63.

[16] Bradford MM. A rapid and sensitive method for the quantitation of microgram quantities of protein utilizing the principle of proteindye binding. Anal Biochem 1976; 72: 248-54.

[17] Sedlak J, Lindsay RH. Estimation of total, protein-bound, and nonprotein sulfhydryl groups in tissue with Ellman's reagent. Anal Biochem 1968; 25(1): 192-205.

[18] Jiang ZY, Woollard AC, Wolff SP. Lipid hydroperoxide measurement by oxidation of $\mathrm{Fe} 2+$ in the presence of xylenol orange. Comparison with the TBA assay and an iodometric method. Lipids 1991; 26(10): 853-6.

[19] Jiang ZY, Hunt JV, Wolff SP. Ferrous ion oxidation in the presence of xylenol orange for detection of lipid hydroperoxide in low density lipoprotein. Anal Biochem 1992; 202(2): 384-9.

[20] Crouch RK, Gandy SE, Kimsey G, et al. The inhibition of islet superoxide dismutase by diabetogenic drugs. Diabetes 1981; 30(3): 235-41.

[21] Aebi H. Catalase in vitro. Methods Enzymol 1984; 105: 121-6.

[22] Costa DD, Neto FF, Costa MD, et al. Vitellogenesis and other physiological responses induced by 17-beta-estradiol in males of freshwater fish Rhamdia quelen. Comp Biochem Physiol C Toxicol Pharmacol 2010; 151(2): 248-57. 
[23] Levine RL, Williams JA, Stadtman ER, Shacter E. Carbonyl assays for determination of oxidatively modified proteins. Methods Enzymol 1994; 233: 346-57.

[24] Sengupta P. The laboratory rat: relating its age with human's. Int J Prev Med 2013; 4(6): 624-30.

[25] Cossio-Bolaños M, Campos GR, Vitoria VR, et al. Reference curves for assessing the physical growth of male Wistar rats. Nutr Hosp 2013; 28(6): 2151-6.

[26] Davydov VV, Shvets VN. Lipid peroxidation in the heart of adult and old rats during immobilization stress. Exp Gerontol 2001; 36(7): 1155-60.

[27] Farooqui MY, Day WW, Zamorano DM. Glutathione and lipid peroxidation in the aging rat. Comp Biochem Physiol B 1987; 88(1): $177-80$

[28] Dyck JRB, Sung MMY. Energy metabolism in the aging heart. Heart Metab 2011; 5: pp. 3-7.
[29] Aguila MB, Mandarim-de-Lacerda CA, Apfel MI. Stereology of the myocardium in young and aged rats. Arq Bras Cardiol 1998; 70(2): 105-9.

[30] Reiss U, Gershon D. Comparison of cytoplasmic superoxide dismutase in liver, heart and brain of aging rats and mice. Biochem Biophys Res Commun 1976; 73(2): 255-62.

[31] Sekhar RV, McKay SV, Patel SG, et al. Glutathione synthesis is diminished in patients with uncontrolled diabetes and restored by dietary supplementation with cysteine and glycine. Diabetes Care 2011; 34(1): 162-7.

[32] Solak ZA, Kabaroğlu C, Cok G, et al. Effect of different levels of cigarette smoking on lipid peroxidation, glutathione enzymes and paraoxonase 1 activity in healthy people. Clin Exp Med 2005; 5(3): 99-105.

(C) Marques et al.; Licensee Bentham Open.

This is an open access article licensed under the terms of the Creative Commons Attribution Non-Commercial License (http://creativecommons.org/licenses/by$\mathrm{nc} / 3.0 /$ ), which permits unrestricted, non-commercial use, distribution and reproduction in any medium, provided the work is properly cited. 